\title{
Investigation of a 7-Level Inverter-based Electric Spring Subjected to Distribution Network Dynamics
}

\author{
K.K.Deepika ${ }^{1}$ \\ Dept. of EEE, VIIT, Visakhapatnam, Andhra Pradesh \\ Scholar, KLEF, Vijayawada,A.P., India
}

\author{
Dr. G.Kesava Rao ${ }^{2}$ \\ Professor, Department of EEE \\ KL EF, Vijayawada, Andhra Pradesh
}

\author{
Dr. J. Vijaya Kumar ${ }^{3}$ \\ Professor, Dept. of EEE, ANITS \\ Visakhapatnam, Andhra Pradesh, INDIA
}

\author{
Dr. Satya Ravi Sankar Rai ${ }^{4}$ \\ Dept. of EEE, Vignan's Institute of Information Technology \\ Visakhapatnam, Andhra Pradesh, India
}

\begin{abstract}
This paper aims to provide solution to mitigate the voltage variations in critical load caused by the high penetration of DGs into distribution system using Electric Springs (ES). In this regard, there is a need for its exploration with various converter circuits. The improvised topology opens new avenues in the renewable energy powered micro grids for the implementation of ES with a Multi-Level Inverter (MLI) comprising a voltage balancing circuit providing a better quality of power system stability and voltage regulation. This paper captures the voltage dynamics of distribution system dominated by Renewable variability for varying reactive power of the DGs and constantly changing consumer demands. These are analyzed and explained using voltage profiles and power flows in Matlab/Simulink environment. It is practically shown that with the developed ES topology \% THD in the system is conspicuously reduced and voltage regulation is seamlessly improved.
\end{abstract}

Keywords-Electric spring; critical load; multilevel inverter; voltage balancing circuit; voltage regulation

\section{INTRODUCTION}

Increasing Distributed Generation in Smart Grid systems impacts the reactive power flow in the feeder and thereby leads to voltage variations in the distribution system [1]. Also, constantly fluctuating consumer load demands effect the load of the distribution system. It is observed that the distribution system is prone to voltage collapse under critical loading conditions. There are several strategies to maintain power quality in the distribution network [2] strengthened through proper placement of the devices [3]. Another way of providing the solution is Demand Side Management (DSM) wherein power demand follows the supply [4]. Creation of new technologies in research, stimulate to achieve the Sustainable Development Goals established by the United Nations (2015) [5]. Among the various profound DSM technologies, Electric spring has emerged to provide voltage and frequency regulation [6][7]. When embedded within a less voltage sensitive load, ES forms a smart load and enables the demand to follow the Renewable variability. The improved regulation is practically executed with power electronics.

In the emerging paradigm of power electronics, balancing the number of power switches, harmonic distortion with the preferred multilevel inverters and investigation with diverse
PWM schemes [8] is important to meet the requirements of the microgrids and nanogrids [9]. Existing inverter topologies for ES focused on the \%THD, number of switches and PWM techniques [10], but there is not a method that would attend to the concern of frequent non-critical load changes, in addition to the former phenomena. This paper explores the relation between dynamic loads and various modes of operation of MLI based ES. Switching operation of the loads influences the PCC voltage. This influence is efficiently handled and the same is evidently illustrated in the 4 case studies.

\section{WORKING OF MLI BASED ELCETRIC SPRING}

Electric Spring is a new voltage compensating device employed in smart grids using demand side management. As shown in Fig. 1, this custom power device is connected in series with a less voltage sensitive load like refrigerator, music system, etc. that have inbuilt Switched Mode Power Supply circuit to withstand voltage variations. This comprises a smart load. Smart load is connected across voltage sensitive load, termed as critical load, to maintain voltage constant. ES senses the voltage fluctuations line voltage, $\mathrm{V}_{\mathrm{s}}$ with respect to its reference voltage, $\mathrm{V}_{\mathrm{s} \_ \text {ref }}$ and operates analogous to mechanical spring [11], as outlined in Table I. The magnitude and phase of the voltage injected by the ES is controlled by the ES controller. Existing inverter topologies for ES [12]-[14] focused on the \%THD, number of switches and PWM techniques. A major benefit of realizing 7-level output voltage with the topology under consideration [15] as illustrated in Fig. 2 is reduction in number of power switches and reduced switching losses. The proposed ES configuration consists of 8 MOSFETS, 4 diodes and 3 capacitors for input voltage division.

TABLE. I. ANALOGY OF MECHANICAL AND ELECTRIC SPRING

\begin{tabular}{|l|l|l|l|}
\hline \multicolumn{2}{|l|}{ Mechanical spring } & \multicolumn{2}{|l|}{ Electric spring } \\
\hline $\begin{array}{l}\text { State of } \\
\text { spring }\end{array}$ & $\begin{array}{l}\text { Mode of } \\
\text { Operation }\end{array}$ & State of voltage & Mode of Operation \\
\hline Neutral & Neutral position & $\mathrm{Vs}=\mathrm{Vs} \_$ref & Neutral \\
\hline Compressed & $\begin{array}{l}\text { Mechanical push } \\
\text { (upward force) }\end{array}$ & $\mathrm{Vs}<\mathrm{Vs}$ ref & $\begin{array}{l}\text { Capacitive Mode } \\
\text { (voltage boosting) }\end{array}$ \\
\hline Extended & $\begin{array}{l}\text { Mechanical pull } \\
\text { (downward force) }\end{array}$ & $\mathrm{Vs}>\mathrm{Vs}$ _ref & $\begin{array}{l}\text { Inductive Mode } \\
\text { (voltage reduction) }\end{array}$ \\
\hline
\end{tabular}




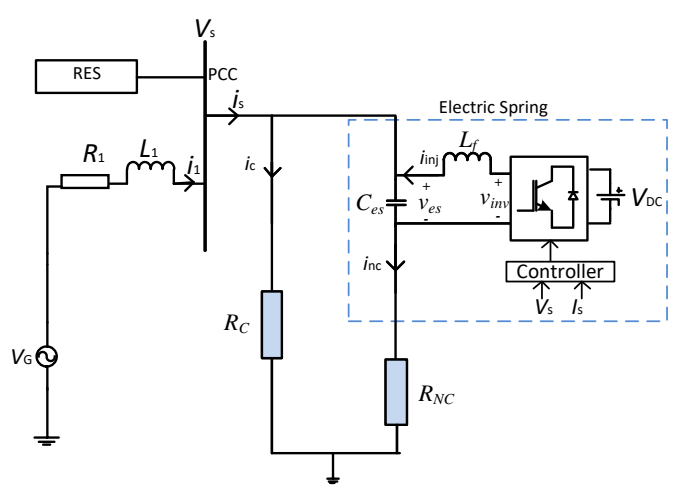

Fig. 1. Electric Spring in a Distribution System.

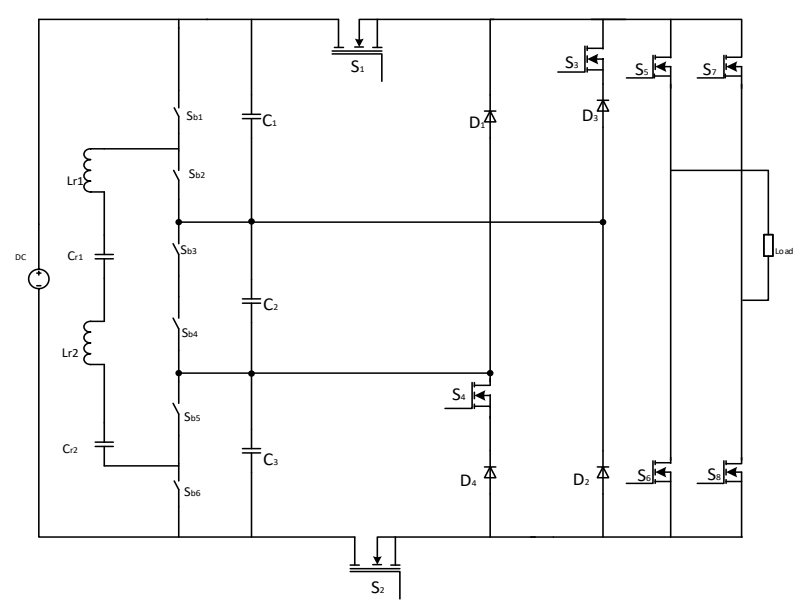

Fig. 2. A 7-Level Inverter Topology for Implementation to ES.

\section{A. For Voltage Level $\frac{V d c}{3}$}

For output voltage $\mathrm{V}_{\mathrm{dc}} / 3, \mathrm{~S}_{\mathrm{b} 1}$ and $\mathrm{S}_{\mathrm{b} 3}$ are in ON position and the current flows through capacitor $\mathrm{C}_{1}$, thereby capacitor gets charged during the positive half cycle. Switches $S_{1}, S_{5}, S_{8}$ are turned $\mathrm{ON}$ and capacitor $\mathrm{C}_{1}$ gets discharged. Voltage available at the load terminals is $\mathrm{V}_{\mathrm{dc}} / 3$.

\section{B. For Voltage Level $2 \frac{V d c}{3}$}

For output voltage $2 \mathrm{~V}_{\mathrm{dc}} / 3, \mathrm{~S}_{\mathrm{b} 1}$ and $\mathrm{S}_{\mathrm{b} 5}$ are in ON position and the current flows through capacitor $\mathrm{C}_{1}$ and $\mathrm{C}_{2}$, thereby capacitors $\mathrm{C}_{1 \text { and }} \mathrm{C}_{2}$ get charged during the positive half cycle. Switches $S_{1}, S_{5}, S_{4}$ are turned On and capacitors discharge causing voltage available at the load terminals as $2 \mathrm{~V}_{\mathrm{dc}} / 3$.

\section{For Voltage Level $V_{D C}$}

For output voltage $\mathrm{V}_{\mathrm{dc}}, \mathrm{S}_{\mathrm{b} 1}$ and $\mathrm{S}_{\mathrm{b} 6}$ are in ON position and capacitors $\mathrm{C}_{1}, \mathrm{C}_{2}, \mathrm{C}_{3}$ are charged during the positive half cycle. Switches $S_{1}, S_{5}, S_{8} S_{2}$ are turned ON and capacitors discharge causing voltage available at the load terminals as $\mathrm{V}_{\mathrm{dc}}$.

\section{For Voltage Level $-\frac{V d c}{3}$}

For output voltage $-\mathrm{V}_{\mathrm{dc}} / 3$, switches $\mathrm{S}_{\mathrm{b} 1}$ and $\mathrm{S}_{\mathrm{b} 6}$ of the voltage balancing circuit are in conducting mode and $\mathrm{C}_{3}$ is charged. The capacitor gets discharged through $D_{1}$ and $S_{7}, S_{2}$, $\mathrm{S}_{6}$. The current direction through the load reverses and hence the voltage at the load terminals is $-\frac{V d c}{3}$.
TABLE. II. SWITCHING COMBINATIONS OF MLI

\begin{tabular}{|l|l|l|l|l|l|l|l|l|}
\hline $\begin{array}{l}\text { Output } \\
\text { voltage }\end{array}$ & $\mathbf{S}_{\mathbf{1}}$ & $\mathbf{S}_{\mathbf{2}}$ & $\mathbf{S}_{\mathbf{3}}$ & $\mathbf{S}_{\mathbf{4}}$ & $\mathbf{S}_{\mathbf{5}}$ & $\mathbf{S}_{\mathbf{6}}$ & $\mathbf{S}_{\mathbf{7}}$ & $\mathbf{S}_{\mathbf{8}}$ \\
\hline$+\mathrm{V}_{\mathrm{DC}} / 3$ & 1 & 0 & 0 & 0 & 1 & 0 & 0 & 1 \\
\hline$+2 \mathrm{~V}_{\mathrm{DC}} / 3$ & 1 & 0 & 0 & 1 & 1 & 0 & 0 & 1 \\
\hline$+\mathrm{V}_{\mathrm{DC}}$ & 1 & 1 & 0 & 0 & 1 & 0 & 0 & 1 \\
\hline 0 & 0 & 0 & 0 & 0 & 1 & 0 & 1 & 0 \\
\hline$-\mathrm{V}_{\mathrm{DC}} / 3$ & 0 & 1 & 0 & 0 & 0 & 1 & 1 & 0 \\
\hline$-2 \mathrm{~V}_{\mathrm{DC}} / 3$ & 0 & 1 & 1 & 0 & 0 & 1 & 1 & 0 \\
\hline$-\mathrm{V}_{\mathrm{DC}}$ & 1 & 1 & 0 & 0 & 0 & 1 & 1 & 0 \\
\hline
\end{tabular}

\section{E. For Voltage Level $-2 \frac{V d c}{3}$}

For output voltage $-2 \mathrm{~V}_{\mathrm{dc}} / 3$, during the positive half cycle, switches $S_{b 2}$ and $S_{b 6}$ of the voltage balancing circuit and the capacitors $\mathrm{C}_{2}, \mathrm{C}_{3}$ gets discharged. They discharge through $\mathrm{D}_{3}$, $S_{3}$ and $S_{7}$ in the forward direction and through $S_{6}$ and $S_{2}$ in return direction.

\section{F. For Voltage Level $-V d c$}

For output voltage $-\mathrm{V}_{\mathrm{dc}}$, switches $\mathrm{S}_{\mathrm{b} 1}$ and $\mathrm{S}_{\mathrm{b} 6}$ are in ON position and capacitors $\mathrm{C}_{1}, \mathrm{C}_{2}, \mathrm{C}_{3}$ are charged. Voltage $-\mathrm{V}_{\mathrm{dc}}$ will now be available across the $\mathrm{H}$-bridge terminals. The capacitors will discharge through $S_{1}$ and $S_{7}$ in forward path $S_{2}$ and $\mathrm{S}_{6}$ in return path.

\section{G. For Voltage Level Zero}

For zero output voltage, switches $\mathrm{S}_{\mathrm{b} 2}, \mathrm{~S}_{\mathrm{b} 3}, \mathrm{~S}_{\mathrm{b} 4}, \mathrm{~S}_{\mathrm{b} 5}$ are short circuit and RSCC-1 and RSCC-2 are in working mode. There is no current flow through any of the capacitor hence charging or discharging. Due to the gate pulses given to switches $\mathrm{S}_{5}$ and $\mathrm{S}_{7}$ of MLI are in ON position and the current flows through the load. Switching combinations of the switches of MLI is outlined in Table II, to attain various output voltages.

\section{RESULTS AND DISCUSSION}

Dynamic behavior of the Multi-level inverter based Electric spring is subjected to an important variation of load. Performance of the Multi-level inverter based ES is commanded by the Sine-triangle Pulse Width Modulation (SPWM) to improve the quality of the voltage injected at PCC by ES, in both capacitive and inductive modes of ES.

To substantiate the dynamic voltage regulation capability of the improvised MLI based ES in all its modes, a model as shown in Fig. 3 is simulated in MATLAB/ Simulink environment. Basic parameters of distribution network and Electric Spring are mentioned in Table III. Voltage on LV side is considered as $220 \mathrm{~V}$.

Random variation of $20 \%$ in output of the Distributed generation source is represented by a three phase programmable voltage source. Overall analysis of the new improvised ES is carried out in four ways as detailed in Table IV.

\section{A. Capacitive mode of ES with Proposed Converter Topology}

To illustrate the voltage boosting function of ES, reduction in the line voltage is simulated from $0.4 \mathrm{sec}$ to $0.8 \mathrm{sec}$, as shown in Fig. 4. At $0.4 \mathrm{sec}$, ES initiates to operate in voltage support mode and injects a voltage of 40volts in series with the Non-critical load voltage, to restore the line voltage back 
to its nominal value of 220 Volts. In Fig. 4, waveform of critical load voltage, clearly depicts that ES succeeds to operate in voltage support mode and the load demand of noncritical load to follow the generation. This is accomplished by absorption of real power and supply of reactive power into the system by ES, as shown in Fig. 5 .

TABLE. III. SIMULATION SYSTEM SPECIFICATIONS

\begin{tabular}{|c|c|c|c|c|}
\hline \multicolumn{2}{|l|}{$\begin{array}{l}\text { Specifications of line } \\
\text { and load }\end{array}$} & \multicolumn{3}{|c|}{ Specifications of Electric Spring } \\
\hline $\begin{array}{l}\text { Line Inductance } \\
(\mathrm{mH} / \mathrm{km})\end{array}$ & 1.22 & \multirow{2}{*}{$\begin{array}{l}\text { Low-pass } \\
\text { filter }\end{array}$} & $\begin{array}{l}\text { Inductance } \\
(\mathrm{mH})\end{array}$ & 5 \\
\hline Line Resistance $(\Omega / \mathrm{km})$ & 0.1 & & $\begin{array}{l}\text { Capacitance } \\
(\mu \mathrm{F})\end{array}$ & 13.2 \\
\hline Noncritical Load $(\Omega)$ & 50.5 & \multirow{2}{*}{$\begin{array}{l}\text { PI } \\
\text { Controller }\end{array}$} & $\mathrm{K}_{\mathrm{p}}$ & 2 \\
\hline Critical load Z $(\Omega)$ & 53 & & $\mathrm{~K}_{\mathrm{i}}$ & 1.5 \\
\hline
\end{tabular}

TABLE. IV. SYNTHESIS OF THE BEHAVIOR OF MLI BASED ES FOR VARIOUS CONDITIONS

\begin{tabular}{|l|l|l|l|l|l|}
\hline $\begin{array}{l}\text { Case } \\
\text { Number }\end{array}$ & $\begin{array}{l}\text { Imposed } \\
\text { condition }\end{array}$ & $\begin{array}{l}\text { Load } \\
\text { variation }\end{array}$ & $\begin{array}{l}\text { Line voltage } \\
\text { variation }\end{array}$ & \% THD \\
\hline 1. & Voltage sag & - & $-20 \%$ & 0.42 \\
\hline 2. & Voltage swell & - & $+20 \%$ & 0.42 \\
\hline 3. & $\begin{array}{l}\text { Load switching } \\
\text { during voltage sag }\end{array}$ & $-66.67 \%$ & $-20 \%$ & 0.44 \\
\hline 4. & $\begin{array}{l}\text { Load switching } \\
\text { during voltage swell }\end{array}$ & $-66.67 \%$ & $+20 \%$ & 0.44 \\
\hline
\end{tabular}

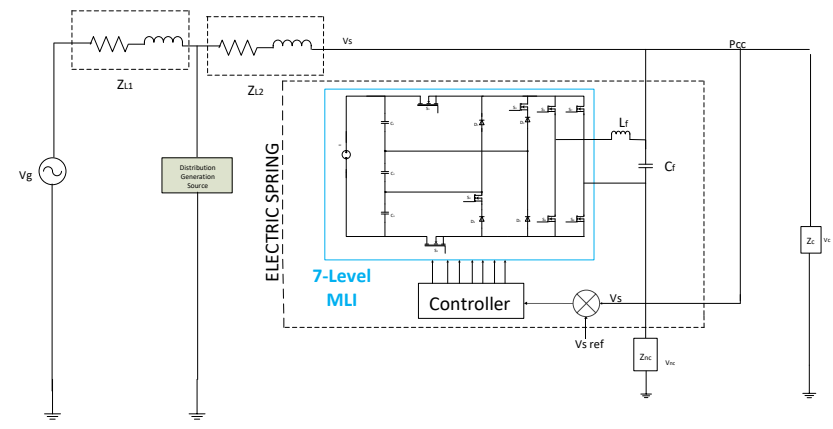

Fig. 3. ES Configuration Comprising a Converter with 8 Switches.

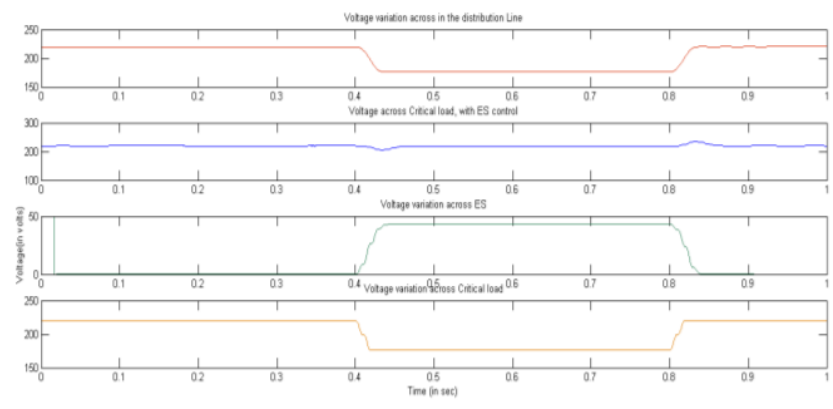

Fig. 4. Simulation Waveforms of Voltages with ES Operation in Capacitive Mode.
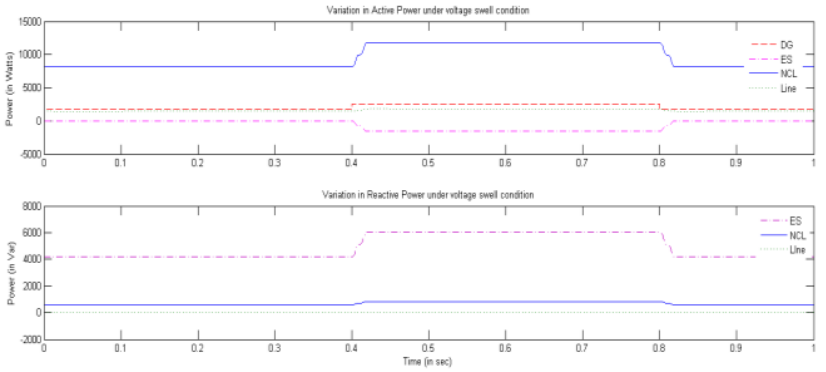

Fig. 5. Simulation Waveforms of Active and Reactive Powers of ES Operation in Capacitive Mode.

\section{B. Inductive mode of ES with Proposed Converter Topology}

To test the Inductive mode of ES, generated power by the DG source is made higher than load demand. This leads to an overvoltage condition simulated from $0.4-0.8 \mathrm{sec}$ and consequent voltage profiles are shown in Fig. 6.

In this condition, ES operates in voltage reduction mode and suppresses the overvoltage. Voltage across ES decreases by 40 volts to restore the line voltage back to its nominal value of 220 Volts. ES maintains the voltage across critical load constant in voltage suppression mode. This is accomplished by injecting real power and absorbing reactive power into system as shown in Fig. 7.

\section{Capacitive mode of ES with Proposed Converter Topology and Dynamic Loading Condition}

To further validate the capability of ES in dynamic loading during capacitive mode of operation, voltage is reduction by $20 \%$ is simulated from 0.4 to $0.8 \mathrm{sec}$ and non-critical load value is reduced at $0.6 \mathrm{sec}$. It is observed in Fig. 8 that the line voltage rises to 265 volts and is seamlessly regulated to 220 volts by ES in about 0.08 seconds. ES effectively boosts the line voltage from $0.4 \mathrm{sec}$ and its regulatory performance is further increased with the dynamic loading at $0.6 \mathrm{sec}$, in addition to the voltage dip in line voltage. Fig. 8 shows that ES regulates the critical load voltage to $220 \mathrm{~V}$ controlling the non-critical load voltage.

\section{Inductive mode of ES with Proposed Converter Topology under Dynamic Loading Condition}

To further validate the capability of ES in dynamic loading during inductive mode of operation, voltage rise by $20 \%$ is simulated from 0.4 to $0.8 \mathrm{sec}$ and non-critical load value is reduced at $0.6 \mathrm{sec}$. It is observed in Fig. 9 that the line voltage rises to 265 volts and is seamlessly regulated to 220 volts by ES in about 0.08 seconds. ES effectively suppresses the line voltage from $0.4 \mathrm{sec}$ and its regulatory performance is further increased with the dynamic loading at $0.6 \mathrm{sec}$, in addition to the overvoltage. Fig. 9 shows that ES regulates the critical load voltage to $220 \mathrm{~V}$ controlling the non-critical load voltage. 


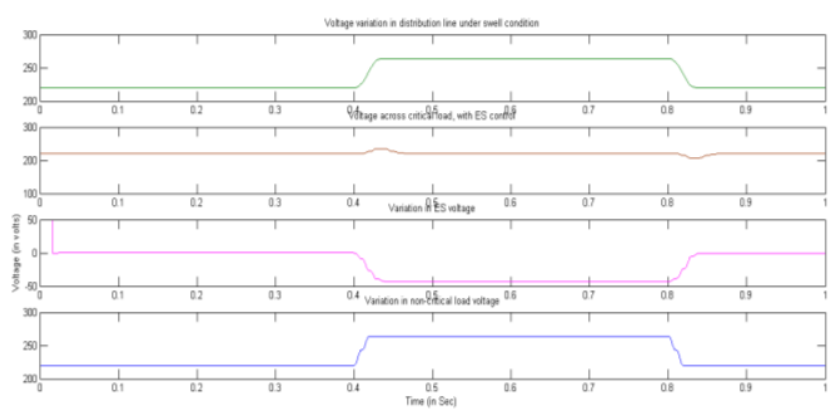

Fig. 6. Simulation Waveforms of Voltages with ES Operation in Inductive Mode
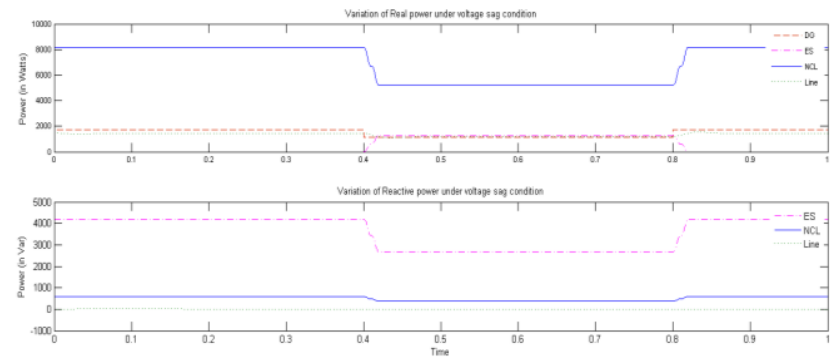

Fig. 7. Simulation Waveforms of Active and Reactive Powers with ES Operation in Inductive Mode.

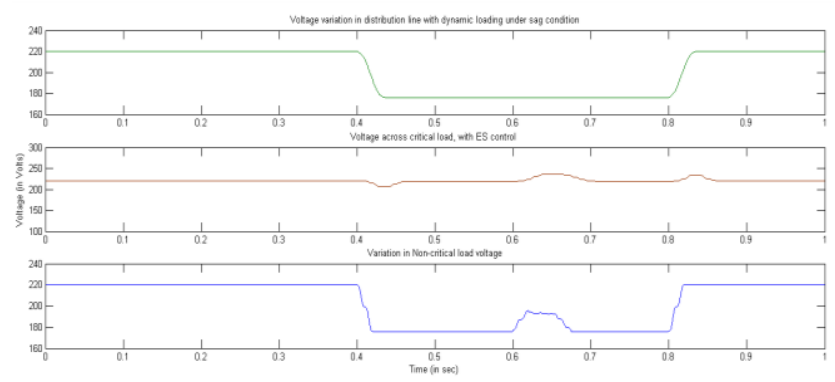

Fig. 8. Variations in Voltages for ES Operation in Capacitive mode with Dynamic Loading Condition.

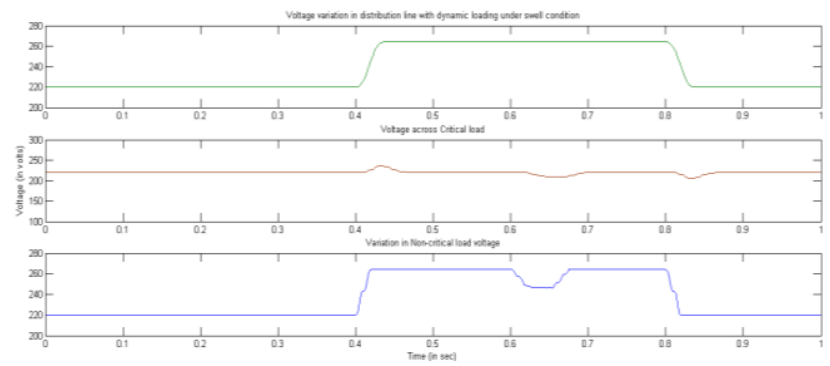

Fig. 9. Variations in Voltages for ES Operation in Inductive mode under Dynamic Loading Condition.

Gate signals given as input to the switches of MLI is illustrated in Fig. 10. These are for the operation of the switches during voltage sag, simulated in case 1 . And the THD in the voltage injected by ES at PCC is $0.42 \%$ as shown in Fig. 11, which is within the standard limits. The fundamental component measures $305 \mathrm{~Hz}$.

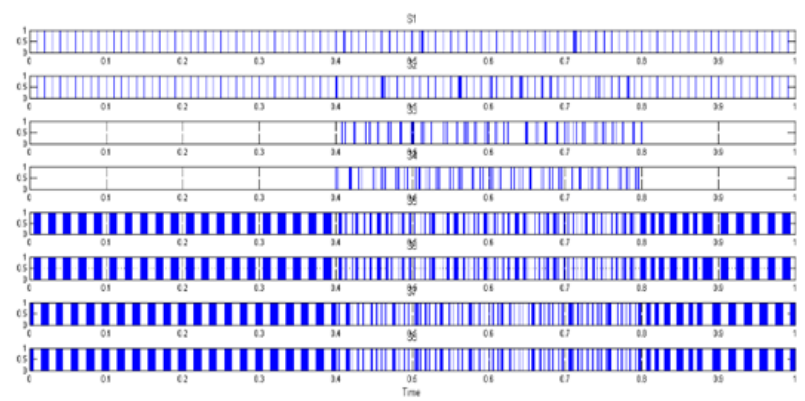

Fig. 10. Gate Signals Fed to the MLI in Capacitive mode of ES.

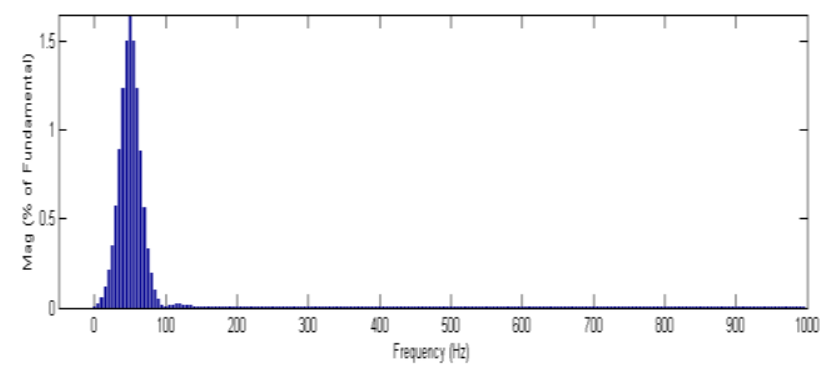

Fig. 11. \% THD in the main Voltage.

\section{CONCLUSION}

This paper presents a new MLI based ES to regulate main voltage in smart grids. The implemented ES controls the injected voltage using a 7 level inverter that has benefits of reduction in the number of switches, switching losses and also \% THD in the local mains voltage. Efficacy of the ES is validated for inductive and capacitive mode of operation. Objectives are discussed with the simulation studies and the results corroborate the effectiveness of improvised topology for ES in its individual modes as well as with dynamic loading conditions.

\section{REFERENCES}

[1] Nazir, Refdinal; NURDIN, Muhammad; FITRIANTO, Eka. Voltage Profile Improvement of the $20 \mathrm{kV}$ Painan Distribution System with Multiple Distributed Renewable Energy Generation. International Journal of Technology, [S.1.], v. 7, n. 1, pp. 26-37, jan. 2016. ISSN 2087-2100. doi:10.14716/ijtech.v7i1.2193.

[2] S. Rahman, "An efficient load model for analyzing demand side management impacts," IEEE Transactions on Power Systems, vol. 8, no. 3, pp. 1219-1226, 1993.

[3] Arief, Ardiaty \& Nappu, Muhammad Bachtiar \& Antamil, Antamil. (2018). Analytical Method for Reactive Power Compensators Allocation. International Journal of Technology. 9. 602. 10.14716/ijtech.v9i3.913.

[4] Chen, Xia \& Hou, Yunhe \& Tan, Siew-Chong \& Lee, C.K. \& Hui, S.Y.. (2014). Mitigating Voltage and Frequency Fluctuation in Microgrids Using Electric Springs. IEEE Transactions on Smart Grid. 6. 10.1109/TSG.2014.2374231.

[5] Berawi, Mohammed Ali. The Role of Technology in Achieving Sustainable Development Goals. International Journal of Technology, [S.1.], v. 8, n. 3, pp. 362-365, Apr. 2017. ISSN 2087-2100. doi:10.14716/ijtech.v8i3.9296.

[6] Chen, Xia \& Hou, Yunhe \& Tan, Siew-Chong \& Lee, C.K. \& Hui, S.Y.. (2014). Mitigating Voltage and Frequency Fluctuation in Microgrids Using Electric Springs. IEEE Transactions on Smart Grid. 6. 10.1109/TSG.2014.2374231. 
[7] Deepika K, Vijayakumar J, G K Rao, Chaitanya S, "Adaptive PI control of Electric Springs for Voltage Regulation under Dynamic Load Changes", International Journal of Innovative Technology and Exploring Engineering, 2019 vol: 8 (10) pp: 1051-1056.

[8] Satiawan, I Nyoman Wahyu et al. Performance Comparison of PWM Schemes of Dual-inverter FED Five-phase Motor Drives. International Journal of Technology, [S.1.], v. 5, n. 3, pp. 277-286, Nov. 2014. ISSN 2087-2100. doi:10.14716/ijtech.v5i3.609.

[9] Andreas, Jamsep \& Setiawan, Eko \& Halim, Suharsono \& Atar, Muhammad \& Nur Shabrina, Hanifati. (2018). Performance Test of 2.5 kW DC Boost Converter for Nanogrid System Applications. International Journal of Technology. 9. 1285. 10.14716/ijtech.v9i6.2429.

[10] Wang, Q.; Deng, F.; Cheng, M.; Buja, G. The State of the Art of Topologies for Electric Springs. Energies 2018, 11, 1724.

[11] S.Y.R.Hui, C.K.Lee, Fu, "Electric springs-A new smart grid technology," IEEE Trans. Smart Grid, vol. 3, no. 3, pp. 1552-1561, September. 2012.
[12] Wamne, S. \& Balpande, P. \& Murme, S. \& Dhakate, Parag \& Bajpai, S. \& Gawande, Snehal \& Nagpure, R. \& Waghmare, Manoj. (2018). A Novel Common Inverter Electric Spring Configuration in Smart Grid. 16. 10.1109/PEDES.2018.8707844.

[13] Rutuja Pawar, S. P. Gawande, S. G. Kadwane, M. A. Waghmare, R. N. Nagpure "Five-Level Diode Clamped Multilevel Inverter (DCMLI) Based Electric Spring for Smart Grid Applications", Energy Procedia 117 (2017) 862-869.

[14] K. Gajbhiye, P. Dahiwale, S. Bharti, R. Pawar, S. P. Gawande and S. G. Kadwane, "Five-level NPC/H-bridge MLI based electric spring for harmonic reduction and voltage regulation," 2017 International Conference on Smart grids, Power and Advanced Control Engineering (ICSPACE), Bangalore, 2017, pp. 203-208.

[15] C. Hsieh, T. Liang, S. Chen and S. Tsai, "Design and Implementation of a Novel Multilevel DC-AC Inverter," in IEEE Transactions on Industry Applications, vol. 52, no. 3, pp. 2436-2443, May-June 2016. doi: 10.1109/TIA.2016.2527622. 